\title{
Communicative Skills: Need of the Day
}

Dharmambal Swaminathan ${ }^{1}$, Kshitija lyer ${ }^{2^{*}}$ and Kapil Gaur ${ }^{3}$

${ }^{1}$ Padma Sarangapani Matriculation Higher Secondary School, Virugambakkam, 2nd Main Rd, Venkatesh Nagar, Nehru Nagar, Saligramam, Chennai, Tamil Nadu 600093, India

${ }^{2}$ M.Sc Integrated Biotechnology, VIT University, Near Katpadi Road, Katpadi, Vellore, Tamil Nadu 632014, India

${ }^{3}$ Deenbandhu Chhotu Ram University of Science and Technology, Murthal, Sonepat, Haryana 131039, India

*Corresponding author: Kshitija lyer, M.Sc Integrated Biotechnology, VIT University, Near Katpadi Road, Katpadi, Vellore, Tamil Nadu 632014, India, Tel: +914423760545; E-mail: kshiiyer@gmail.com

Received date: October 28, 2014; Accepted date: October 31, 2014, Publication date: November 07, 2014

Copyright: (c) 2014 Swaminathan D, et al. This is an open-access article distributed under the terms of the Creative Commons Attribution License, which permits unrestricted use, distribution, and reproduction in any medium, provided the original author and source are credited.

\begin{abstract}
To keep pace with the changing learners needs resulting from social, cultural, psychological and environmental changes happening around the world as a teacher we get ample opportunities to train our students in their individual skill areas.
\end{abstract}

Keywords: Communication; English; Language learning; Grammar

\section{Introduction}

English is not only a language but is considered as one of the pillars of academic. Excellence when it is observer at the world level. Reason, more technical books are published in English. Language learning is aimed at making learner use the language for real life purpose not for communicative purpose only [1].

Learners need to use language to function in professional, academic and social selling. This demands higher order, language and thinking skills. As a part of the learning process, in a specially designed testing environment, it can be made possible through a totally activity based pedagogy pushing the student to:

- $\quad$ LISTEN - With purpose to a variety inputs.

- READ - And understand various text types.

- SPEAK - On contemporary age.

- WRITE - On a range of topics in acceptable error-free English.

Language is the medium through which we communicate. There are few barriers which make our communication ineffective or end up in misunderstanding or basically one is not able to communicate even. As such language is not learnt but acquired. That is we use L-S-R-W method. Till the age of 3 - Listening and from the age of 3 -- speaking broken words. Later read from pictures and finally write. When one is not able to communicate effectively then we become aware of the barriers. Some of the barriers are homophones and spellings, assumptions not but the most important one the accent. These are language barriers. Some personal barriers are inattentiveness, lack of confidence, fear and individual perception [2].

One has to overcome all these. The best methods are reading a lot of books as reading make a man perfect. It helps one to use precise word which conveys ones thought clearly. Every sentence one utters must have not more than eight simple and easy words. Improving ones listening power and know the audience one is going to talk to. To be an effective speaker, keep a check over the tone, meter and vocabulary. Synchronizing one's body language and avoiding slang language or local dialect too helps. Perfect pronunciation enchants the audience attention and creates interest in the subject one is speaking about.

Nature and characteristic of the class room should make the teacher use various teaching techniques: can even adopt various methods and explore new ways and means of enabling learner engage with the language in and out of the classroom too $[3,4]$.

Besides punctuation, grammar and vocabulary teacher's personal skills and motivational skill helps in tuning and scraping the trapped communicative skill in a child.

\section{Communicative skill plays a major role in efficient expression of language}

In Sanskrit (a language in India) its" wak chathuriam" or Power of Communicative Skill one is on his way to success. Usage of appropriate word at appropriate place not only emphasizes its value but is very effective. Conversational comfort could be achieved by the ability to converse on various topics with confidence.

An English word for every local language word commonly used and for the same local Folk songs and lullabies can be translated and sung in English by students. This helps students to increase their vocabulary in English language. Fun and frolic filled way not only creates inquisitiveness in students but with their knowledge they end up conversing in English [5].

This inculcating procedure for creating interest in communicative skills in English yields encouraging results. Changes can be seen if the library in charge at school level keeps a check on what type of books a student has been issuing or even parents can find out what their wards are reading on line home $[2,3]$.

When students read some story book in the class room, teacher can conduct quiz based on that story. Can even frame some grammar based question, say change the sentences to past tense or just frame sentences by changing the Adjectives to their opposite. This could be lot of fun! One could say why only quizzing because: Quizzing or fishing matches a lot. People who love fishing study and practice it.

- They learn which tool is good for fishing the best fish. 
Page 2 of 2

- What type of fish is available in which type of water?

- No one is born with fishing talent.

- Similarly conversing or learning a language which is your mother do not tongue nor spoken in the surroundings is where you live not an inborn talent.

- Some enjoy more than others, but everyone can do it if they want to.

- The question set should help the students acquire the mysterious and covert power of the pen strengthening their grammatical governance.

- Most of the questions must be from our daily life, so that the students get a idea from the illustrations that practicing such skill do help in empowering their English language.

- They can even efficiently apply in their future pursuance of the language.

Academically weak but most active students sometime give a very good grammatically perfect extempore speech on the stage shocking everyone! When encouraged and appreciated in front of the audience, result is stunning! Thus Self-motivated student's tremendous Academic improvement is seen in their future performance [5]

\section{References}

1. Tom Hayton (2009) Google and the lexical approach.

2. Books from Department of English and foreign languages SRM University.

3. Ankit A (2014) Motives of Arabic Speaking Viewers for Watching English or Dubbed TV Programs. J Mass Communicat Journalism 4: 174.

4. Pritchard C, Silk A (2014) A Case-Study Survey of an Eight-year Cluster of Motor Neurone Disease (MND) Referrals in a Rural English Village: Exploring Possible Aetiological Influences in a Hypothesis Stimulating Study. J Neurol Disord 2: 147.

5. Stannard JE (2012) The Englishman’s Castle. J Civil Legal Sci 1: e107. 